\title{
Wolf Use of Humanmade Objects During Pup-rearing
}

\author{
David E. Ausband \\ U.S. Geological Survey, Idaho Cooperative Fish and Wildlife Research Unit, Department of Fish and Wildlife Sciences \\ Corresponding author (Email: dausband@uidaho.edu)
}

Citation - Ausband, D. E. (2021). Wolf use of humanmade objects during pup-rearing. Animal Behavior and Cognition, 8(3), 405-414. https://doi.org/10.26451/abc.08.03.06.2021

\begin{abstract}
Some animals use humanmade objects for building and constructing nests or shelter and even for play. Gray wolves (Canis lupus) gather and use humanmade objects discovered in their natural environment. Gathering humanmade objects is a peculiar behavior particularly when there is no immediately apparent benefit to survival or reproduction. I opportunistically documented 46 different types of humanmade objects with plastic bottles and aluminum cans being the most common items found at wolf pup-rearing sites. Many objects were made of materials that appeared suitable to alleviate pain in teething pups. For some objects, however, it was not immediately obvious that they would alleviate teething pain due to their unpliable material. Additionally, such objects were quite rare in wolves' natural environment although it was not uncommon to find them at pup-rearing sites. Rare humanmade objects may provide a novelty that stimulates pups more than common objects. I hypothesize that objects used by wolf pups 1) alleviate pain from teething, and 2) provide adults respite from energetic pups. The latter is an important distinction because it implies the benefit of object play is to the adults and not the pups per se. Gathering novel objects that occupy energetic and hungry pups may influence the overall ability of social carnivores to leave young unattended while they hunt, to rest upon their return, and ultimately rear young successfully.
\end{abstract}

Keywords - Canis lupus, Gray wolves, Human, Object play, Play, Pups, Reproduction

Many animals gather and use objects from the surrounding natural environment to construct nests, manipulate water flows, forage, and even protect themselves from the elements (Baker \& Hill, 2003; Boesch, 2013; Layne, 2003). One of the most famous use of objects is the structure built by male bowerbirds (Ptilonorhynchus violaceus) and adorned with colorful objects to attract females and enhance reproductive success (Borgia, 1985). Once thought almost nonexistent outside of humans, a wide variety of species even use naturally occurring objects for tools (Sanz et al., 2013). Some species also appear to use objects in their environment for play often with no apparent benefit to survival or reproduction (Bekoff \& Byers, 1998; Owen et al., 2012).

While it is quite common for animals to use objects from the natural environment, some species make use of humanmade objects as well. For example, black kites (Milvus migrans) often construct nests inserted with many small pieces of white plastic that are used to enhance conspicuousness and advertise nests to rivals (Canal et al., 2016, Sergio et al., 2011). Similarly, human artifacts (e.g., arrowheads) several hundred years old have been found in the nests of bushy-tailed wood rats (Neotoma cinerea; Tuohy, 1982). Although most use of humanmade objects is for building and constructing of nests or shelter, there are accounts of wild animals inspecting and, in some cases, appearing to play with humanmade objects. For example, the novelty of a manmade object influences how attractive it is to corvids, but such objects are often quickly ignored after they are discovered to be inedible (Heinrich, 1995). Some animals' use of inedible objects is believed to sharpen their skills for future problem-solving 
(Auersperg et al., 2015). Overall, most documentation of animals using humanmade objects for play has come from subjects in captivity (Hall, 1998; Paquette \& Prescott, 1988) and fewer examples exist in wild, free-ranging animals (Herzing et al., 2012; Nahallage et al., 2016; Paulos et al., 2010).

Gray wolves (Canis lupus) are one example of an animal that gathers and uses humanmade objects possibly for play. Wolves are social carnivores that rear pups at communal areas (i.e., pup-rearing sites). Such areas are locations where adult group members provision and rest with the pups in between foraging bouts until pups are large enough (approximately 6 months old) to travel with the group on hunts. Such pup-rearing sites are ideal places to gain insights into wolf behavior due to the amount of time wolves spend there (approx. 3 weeks per site; Ausband et al., 2016) and because they are highly mobile during other times of year, making behavioral study difficult. While conducting fieldwork at puprearing sites to monitor and research gray wolves in western North America, the author and collaborators have frequently discovered humanmade objects that appear to have been used as toys based on numerous bite marks, shredding, and their frequent location in the activity center, or play area, at pup-rearing sites (Joslin, 1967).

Gathering humanmade objects is a peculiar behavior, particularly when there is no immediately apparent benefit to survival or reproduction. However, Greene et al. (2011) suggest "object play is a type of play that incorporates novel experiences, which is a cognitively demanding process and thus may have evolved in species that possess the required cognitive abilities" (p. 295). Using the existing literature, I identified three potential reasons for such object gathering behavior; 1) for shelter/nesting, 2) to attract mates, and 3) for play (Bekoff \& Byers, 1998; Borgia, 1985; Sanz et al., 2013). Here I provide a brief summary of humanmade objects found at wolf pup-rearing sites and posit that wolves gather humanmade objects to give to pups for play and to alleviate pain from teething. Furthermore, it appears novel objects that are likely to be quite rare in wolves' natural environment are particularly coveted.

\section{Method}

\section{Study Areas}

From 2006-2020, we conducted surveys at pup-rearing sites in Idaho, Montana, southwest Alberta, Canada, and Yellowstone National Park, Wyoming, USA. Surveys in these areas were conducted as part of population monitoring required by the Endangered Species Act and for research that sought to obtain genetic samples for studies testing new techniques for population monitoring (Stenglein et al., 2010) and exploring the effects of hunting and trapping on gray wolves (Ausband et al., 2017).

\section{Field Surveys}

When available, we used radiotelemetry locations of wolves to locate pup-rearing sites. Wolves were radiocollared as part of population monitoring conducted by Idaho Department of Fish and Game (IDFG), Montana Fish, Wildlife and Parks, Nez Perce Tribe, U.S. Fish and Wildlife Service, and Yellowstone National Park. Animal handling adhered to stringent protocols ensuring animal safety and aligned with capture protocols and handling procedures of wolves aligned with guidelines of the American Society of Mammalogists and were further approved by The University of Montana IACUC Animal Use Protocol 008-09MMMCWRU. In areas that did not contain radiocollared wolves, we surveyed at historical pup-rearing sites and sites predicted by a habitat model (Ausband et al., 2010) to be highly suitable habitat ( $\geq 70 \%$ suitability).

In addition to the author's own documentation, eight project collaborators were asked to describe humanmade objects found at wolf pup-rearing sites. Each collaborator had $\geq 2$ years field experience surveying rendezvous sites for wolves (total 55 years of experience). At occupied or recently occupied pup-rearing sites, we located the activity center and 4-8 technicians traversed the site to collect pup and adult scat samples for 3-4 hours. Some personnel recorded notes about humanmade objects discovered at 
pup-rearing sites, but this was not always completed and the subsequent tally of objects found is not comprehensive.

\section{Results}

Humanmade objects are not usually found at kill sites or resting sites used during other times of year (D. Ausband, US Geological Survey, personal observation; J. Husseman, IDFG, personal observation). Biologists documented 46 different types of humanmade objects found at pup-rearing sites (Table 1). The most common objects were plastic bottles (PETE, HDPE), plastic (HDPE) whose source object was unidentifiable, and aluminum cans.

\section{Table 1}

Humanmade Objects Found at Gray Wolf Pup-Rearing Sites (i.e., Rendezvous Sites) in Idaho, Montana, Yellowstone National Park, Wyoming, USA and Alberta, Canada, 2006-2020

\begin{tabular}{|c|c|c|}
\hline Frequency & Object & Object \\
\hline Common & Plastic bottles $\left(\mathrm{PETE}^{1}\right)$ & Plastic bottles/jugs (HDPE²) \\
\hline Common & Aluminum cans & Unidentifiable source, plastic $\left(\mathrm{HDPE}^{2}\right)$ \\
\hline Common & Tin cans & Leather gloves \\
\hline Common & Plastic food pouch (e.g., juice drink) & Zippered plastic storage bags \\
\hline Less common & Cellophane balloons & Plastic garbage bags \\
\hline Rare & Portable compact disc player & Shoe/boot outsoles and insoles \\
\hline Rare & Plastic drinking canteen & Sandals and flip flops \\
\hline Rare & Handgun magazine with bullets & Football \\
\hline Rare & Plastic utensils & Plastic tree felling wedge \\
\hline Rare & Rubber balloon & Nylon tent body \\
\hline Rare & Shotgun shells & Plastic fuel can lid \\
\hline Rare & Ice scraper & Large rope \\
\hline Rare & Two-way radio/GPS unit & Reusable plastic water bottle \\
\hline Rare & Plastic flashlight & Hammer \\
\hline Rare & Frisbee golf disk & Tin measuring cup \\
\hline Rare & Plastic health insurance ID cards & Digital camera \\
\hline Rare & Chainsaw air filter & Spray paint can \\
\hline Rare & Chainsaw scabbard & Automotive car washing brush \\
\hline Rare & Cotton fabric (shirt or pant seam) & Prescription bottle \\
\hline Rare & Metal multitool & Fabric flower decorations \\
\hline Rare & Carpet scraps & Metal chain \\
\hline Rare & Rifle mount for ATV & Snowmobile mudflap \\
\hline Rare & Cooking pan & Sweatshirt \\
\hline
\end{tabular}

Note. ${ }^{1}$ Polyethylene terephthalate (PETE); ${ }^{2}$ High-Density Polyethylene (HDPE)

It appears that wolves transport objects to pup-rearing sites, because many of the objects we observed were unlikely to have been there before wolves occupied the site (e.g., digital camera, sandal; Table 1, Figure 1). Additionally, we documented four instances further suggesting that wolves transport humanmade objects to pup-rearing sites. Specifically, 1) in approximately 2008, a biologist for IDFG observed a wolf transporting a plastic traffic cone in the vicinity of a pup-rearing site, 2) in 2009 , an 
IDFG biologist observed a wolf carrying a plastic HDPE water jug away from their campsite, which was very close to a pup-rearing site, 3 ) in 2013, the author observed carpet strips in a pup-rearing site and later found the source carpet at a camping area $3.2 \mathrm{~km}$ distant, and 4) in 2017, the author obtained images of pups carrying a can as they moved from their den site to a second pup-rearing site some $3.0 \mathrm{~km}$ distant in early summer (Figures 2A,B).

\section{Figure 1}

Sandal Found and Evidently Used as a Toy at a Wolf Pup-Rearing Site in the Sawtooth Wilderness Area, Idaho, USA

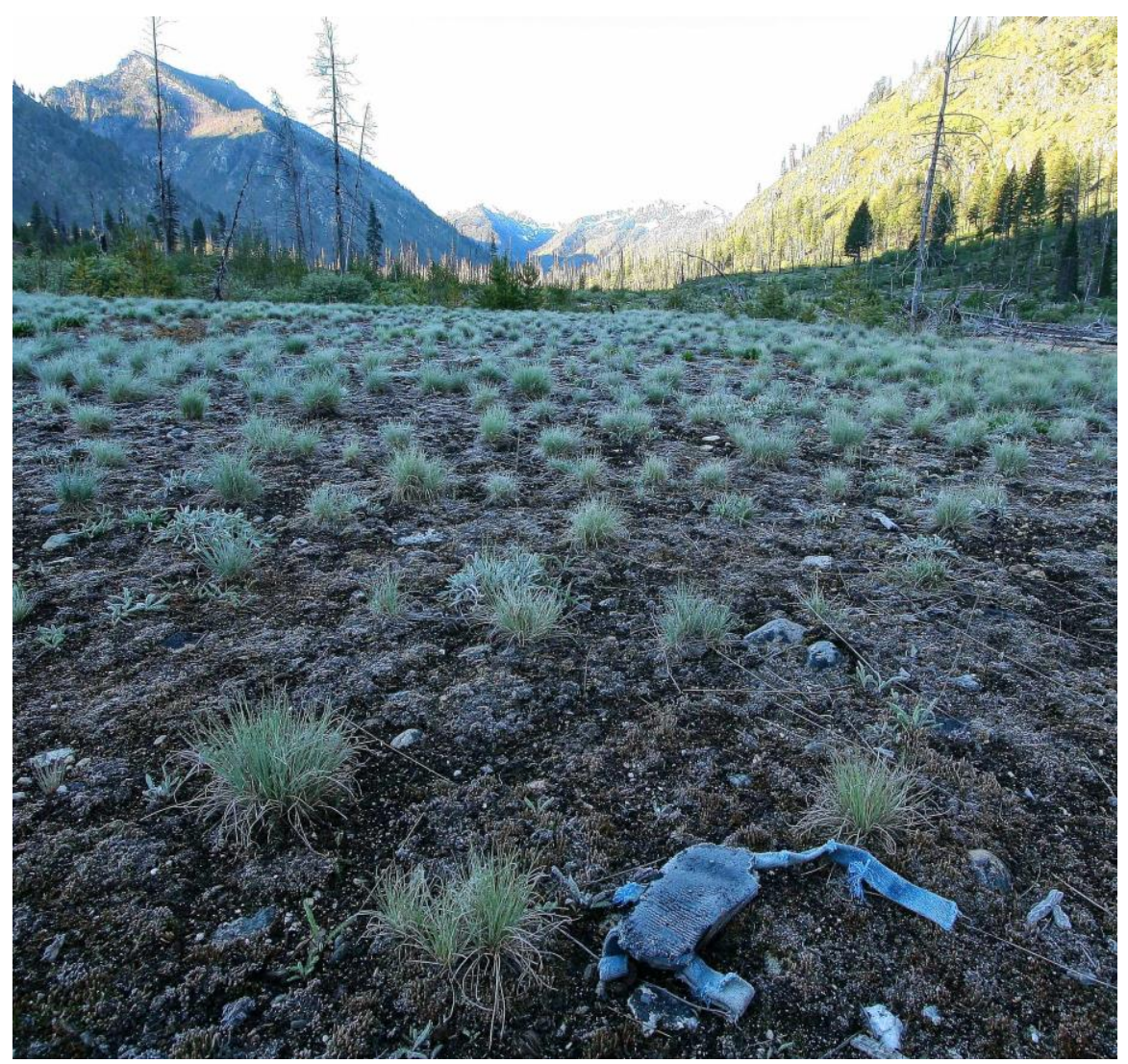

\section{Discussion}

Collection, transport, and subsequent use of humanmade objects is a relatively rare behavior in animals and, in wolves, appears to be associated with rearing young. Although adult wolves may have gathered humanmade objects for their own use and not for pups, object play in adults is much less common than in juveniles (Hall, 1998). Regardless of whether adults transport objects for themselves or for pups as I hypothesize, such behavior is quite rare in free-ranging animals. It is possible that wolf pups gather humanmade objects themselves particularly as they grow and begin to go on brief forays away from pup-rearing sites (Mills et al., 2008) or during moves between pup-rearing sites as I documented (Figs 2A, B). Some objects had punctures and bite marks consistent with very young, fairly immobile pups that do not wander from pup-rearing sites (Figures. 3A, B). Hence, it appears that adults bring at least some objects back to pups.

Some wild animals have been shown to use humanmade objects for nesting or shelter; few examples exist of their utilization for play (Paulos et al., 2010). Domestic dog pups use objects for play at a very early age prior to weaning, suggesting such interactions are not associated with hunger and are indeed object play (Burghardt et al., 2016). We have a strong foundation for understanding the various 
effects of group composition, breeder condition, and even environmental fluctuations on reproduction in social carnivores (Ausband et al., 2017; Bateman et al., 2011; Brainerd et al., 2008; Stahler et al., 2013). More nuanced behaviors, such as gathering objects to occupy energetic and hungry pups may influence the overall ability of social carnivores to leave young unattended while they hunt, to rest upon their return, and ultimately rear young successfully.

\section{Figure 2}

Gray Wolf Pups Playing With an Aluminum Can (A) and (B) a Single Individual Carrying the Can During a Movement Between the Pack's Den and Second Pup-Rearing site (i.e., Rendezvous Site) in Idaho, USA, 2017
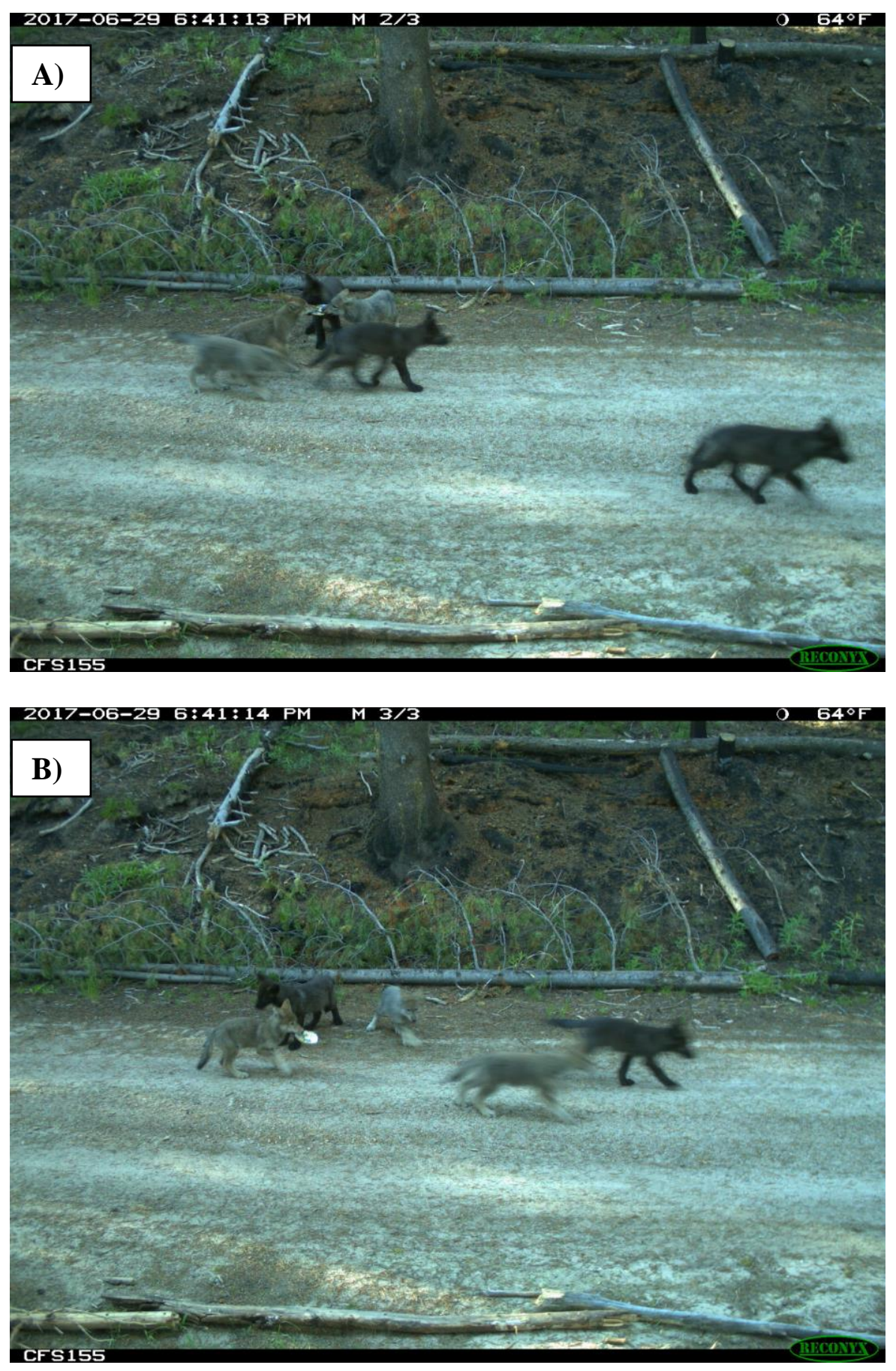


\section{Figure 3}

Humanmade Objects Found at Wolf Pup-Rearing Sites in Idaho and Yellowstone National Park, Wyoming, USA
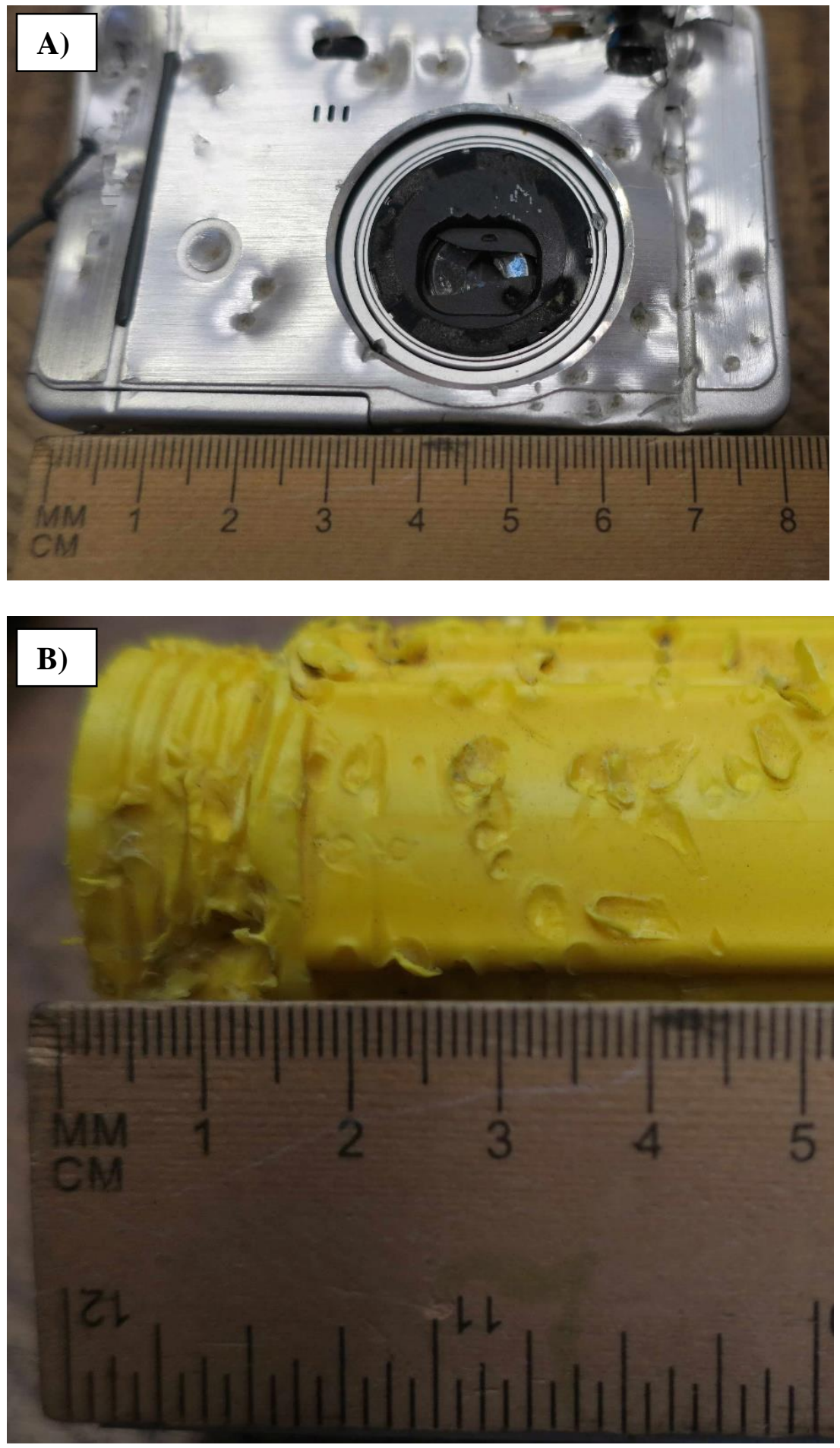

Note. a) Small punctures and bite marks indicate use by young wolf pups while canines were still quite sharp, b) Adult wolf canine teeth are generally $\geq 4 \mathrm{~mm}$ at the tip. 
Why trash? Why not use only objects common in the natural environment such as sticks and branches? There appears to be at least some attraction to the novelty of humanmade objects because they are exceedingly rare in wolves' natural environment compared to the relative abundance of sticks and branches. Humanmade objects derived from chewy, yet durable materials (e.g., PETE, HDPE plastics) are common at pup-rearing sites and they are also likely to be the most abundant humanmade objects in wolves' environment. Common objects made from fairly soft, chewy materials (e.g., plastic bottle) typically contained numerous bite marks and shredding where chewing had clearly occurred. But why do wolves also use novel objects that are quite rare in their environment and are unlikely to alleviate pain associated with teething (e.g., metal chain; Table 1)? This is made additionally puzzling because such objects could also be indicative of the dangers associated with mortality from human baits and poisons, which are often in the form of novel scents and objects (Shivik et al., 2014). I posit that because novel objects are rare, they may be coveted by individual pups leading to social play (Bekoff \& Allen, 1998; Biben, 1982, 1983), aggressive interactions between individuals, and ultimately the solidification of dominance hierarchies (Biben, 1998). The latter is a facet particularly important in wolf sociality and life history (Packard, 2003). Wolf pups in captivity show a very early propensity for exploration and novel stimuli (Lord, 2013).

Because adult wolves returning from successful hunts are typically carrying food in their mouths or stomachs (Packard, 2003), novel objects may be brought back by adults more frequently after unsuccessful hunts perhaps to assuage hungry pups. If true, one might predict that novel objects would be more abundant at pup-rearing sites during times of prey scarcity. Novelty may lead to pups being occupied for longer periods of time allowing adults to rest uninterrupted after returning from nighttime foraging (Theuerkauf et al., 2003). In human children, for example, multiple individuals played with novel toys for longer periods of time than familiar toys (Rabinowitz et al., 1975).

I hypothesize that objects used by wolves served the purposes of 1) alleviating pain from teething, and 2) providing adults respite from energetic pups. That novel objects provide respite for adults is an important distinction because it implies the benefit of object play is to the adults and not the pups per se. The use of humanmade objects as toys is widespread in wolves at least in the Northern Rocky Mountains of the U.S.

Wolves did not use humanmade objects to construct shelter, or seemingly advertise their presence to rivals because we did not typically find objects in any sort of constructed shape or prominent areas that would be readily observed by conspecifics. It is also unlikely that wolves gather humanmade objects to attract mates because the use of such objects appears limited to the pup-rearing season, well after the breeding period and female estrus has ended. Although not conclusive, I provide several examples suggesting adult wolves transport humanmade objects to pup-rearing sites. In addition, many of the areas where we studied wolves were remote, far from human habitation and, in many cases, even primitive camping sites. In most cases, it is unlikely that wolves found the humanmade objects that we observed already present at the pup-rearing site.

I used opportunistic sampling to describe a unique behavior in gray wolves; thus, my inferences are limited. Further efforts exploring the mechanisms behind this behavior can benefit from systematic sampling and observations (visual or cameras) of wolves interacting with objects. For example, documenting pup-rearing sites with and without humanmade objects, direct observation of wolves' use of objects at sites, and documentation of which sex and age classes transport humanmade objects to puprearing sites would be insightful. Additionally, testing the genetic relatedness of individuals at sites with and without humanmade objects would provide inferences for predictions arising from kin selection and group augmentation theories. Experimental tests deploying various types of humanmade objects near puprearing sites to determine whether there is a preference for novelty and suppleness of material would shed light on what use humanmade objects serve during pup-rearing.

\section{Data availability statement}

All data used in this manuscript are presented here. 


\section{Animal welfare statement}

Animal handling adhered to stringent protocols ensuring animal safety and aligned with capture protocols and handling procedures of wolves aligned with guidelines of the American Society of Mammalogists and were further approved by The University of Montana IACUC Animal Use Protocol 008-09MMMCWRU.

\section{Acknowledgements}

Field surveys were supported by funding from the Alberta Conservation Association, Alberta Environment and Sustainable Resource Development, Alberta Innovates BioSolutions, Bernice Barbour Foundation, Coypu Foundation, Eppley Foundation for Scientific Research, Idaho Department of Fish and Game, Idaho Fish and Wildlife Foundation, Leonard X. Bosack and Bette M. Kruger Foundation, Nancy Carroll Draper Foundation, Nez Perce Tribe, Oregon Zoo Future for Wildlife grants, Regina Bauer Frankenberg Foundation for Animal Welfare, Rocky Mountain Forest and Range Association, Shikar Safari Club International, Steven Leuthold Family Foundation, The Mountaineers Foundation, University of Idaho Environmental Science Program, U.S. Fish and Wildlife Service, U.S. Geological Survey, Wesley M. Dixon Fellowship at The University of Montana, Wilburforce Foundation, Wolf Recovery Foundation, Yellowstone National Park Wolf Project.

I sincerely thank all field technicians for their efforts during data collection. I also thank S.

Bassing, A. Fahnestock, J. Husseman, J. Krohner, K. Lamp, J. Linch, P. Rebholz, J. Ruprecht and J. Struthers for their information about objects found at pup-rearing sites. I thank M. Mitchell for early manuscript review. Any use of trade, firm or product names is for descriptive purposes only and does not imply endorsement by the US Government. This paper was subject to USGS Fundamental Science Practices https://pubs.usgs.gov/circ/1367).

\section{References}

Auersperg, A. M. I., van Horik, J. O., Bugnyar, T., Kacelnik, A., Emery, N. J., \& von Bayern, A. M. P. (2015). Combinatory actions during object play in psittaciformes (Diopsittaca nobilis, Pionites melanocephala, Cacatua goffini) and corvids (Corvus corax, C. monedula, C. moneduloides). Journal of Comparative Psychology, 129, 62-71.

Ausband D. E., Mitchell M. S., Doherty K., Zager P., Mack C. M., \& Holyan J. (2010). Surveying predicted rendezvous sites to monitor gray wolf populations. Journal of Wildlife Management, 74, 1043-1049.

Ausband, D. E., Bassing, S. B., Mitchell, M. S., Nordhagen, M., Smith, D. W., \& Stahler, D. R. (2016). Dog days of summer: Influences on decision of wolves to move pups. Journal of Mammalogy, 97, 1282-1287.

Ausband, D. E., Mitchell, M. S., Stansbury, C., Stenglein, J. L., \& Waits, L. (2017). Harvest and group effects on pup survival in a cooperative breeder. Proceedings of the Royal Society B., 284. https://doi.org/10.1098/rspb.2017.0580

Baker, B. W., \& Hill, E. P. (2003). Beaver (Castor canadensis). In G. A., Feldhamer., B. C. Thompson, \& J. A. Chapman (Eds.), Wild mammals of North America; Biology, management and conservation (pp. 288-310). The Johns Hopkins University Press.

Bateman, A. W., Coulson, T., \& Clutton-Brock, T. H. (2011). What do simple models reveal about the population dynamics of a cooperatively breeding species? Oikos, 120, 787-794.

Bekoff, M., \& Allen, C. (1998). Intentional communication and social play: How and why animals negotiate and agree to play. In M. Bekoff \& J. A. Byers (Eds.), Animal play: Evolutionary, comparative, and ecological perspectives (pp. 97-114). Cambridge University Press.

Bekoff, M., \& Byers, J. A. (1998). Introduction. In M. Bekoff \& J. A. Byers (Eds.), Animal play: Evolutionary, comparative, and ecological perspectives (pp. xiii-xvi). Cambridge University Press.

Biben, M. (1982). Object play and social treatment of prey and bush dog and crab-eating foxes. Behaviour, 79, 201211.

Biben, M. (1983). Comparative ontogeny of social behavior in three South American canids, the maned wolf, crabeating fox, and bush dog: implications for sociality. Animal Behaviour, 31, 814-826. 
Biben, M. (1998). Squirrel monkey playfighting: Making the case for a cognitive training function for play. In M. Bekoff \& J. A. Byers (Eds.), Animal play: Evolutionary, comparative, and ecological perspectives (pp. 161-182). Cambridge University Press.

Boesch, C. (2013). Ecology and cognition of tool use in chimpanzees. In C. Sanz, J. Call, \& C. Boesch (Eds.), Tool use in animals: cognition and ecology (pp. 21-47). Cambridge University Press.

Borgia, G. (1985). Bower quality, number of decorations and mating success of male satin bowerbirds (Ptilonorhynchus violaceus): An experimental analysis. Animal Behaviour, 33, 266-271.

Brainerd, S. M., Andren, H., Bangs, E. E., Bradley, E. H., Fontaine, J. A., Hall, W., Iliopoulos, Y., Jimenez, M. D., Jozwiak, E.A., Liberg, O., Mack, C.M., Meier, T. J., Niemeyer, C. C., Pedersen, H. C., Sand, H., Schultz, R. N., Smith, D. W., Wabakken, P., \& Wydeven, A. P. (2008). The effects of breeder loss on wolves. Journal of Wildlife Management, 72, 89-98.

Burghardt, G. M., Albright, J. D., \& David, K. M. (2016). Motivation, development, and object play: Comparative perspectives with lessons from dogs. Behaviour, 153, 767-793.

Canal, D., Mulero-Pázmány, M., Negro, J. J., \& Sergio, F. (2016). Decoration increases the conspicuousness of raptor nests. PLOS ONE, 11, e0157440.

Greene, W. E., Melillo-Sweeting, K., \& Dudzinski, K. M. (2011). Comparing object play in captive and wild dolphins. International Journal of Comparative Psychology, 24, 292-306.

Hall, S. L. (1998). Object play by adult animals. In M. Bekoff \& J. A. Byers (Eds.), Animal play: Evolutionary, comparative, and ecological perspectives (pp. 45-60). Cambridge University Press.

Heinrich, B. (1995). Neophilia and exploration in juvenile common ravens, Corvus corax. Animal Behaviour, 50, 695-704.

Herzing, D. L., Fabienne, D., \& Pack, A. A. (2012). Responses of human-habituated wild Atlantic spotted dolphins to play behaviors using a two-way human/dolphin interface. International Journal of Comparative Psychology, 25, 137-165.

Joslin, P. W. B. (1967). Movements and home sites of timber wolves in Algonquin Park. American Zoologist, 7 , $279-288$.

Layne, J. N. (2003). Armadillo, Dasypus novemcinctus. In G. A. Feldhamer, B. C. Thompson, \& J. A. Chapman (Eds.), Wild mammals of North America; Biology, management and conservation. (pp. 75-97). The Johns Hopkins University Press.

Lord, K. (2013). A comparison of the sensory development of wolves (Canis lupus lupus) and dogs (Canis lupus familiaris). Ethology, 119, 110-120.

Mills, K. J., Patterson, B. R., \& Murray, D. L. (2008). Direct estimation of early survival and movements of eastern wolf pups. Journal of Wildlife Management, 72, 949-954.

Nahallage, C. A. D., Baptiste-Leca, J., \& Huffman, M. A. (2016). Stone handling, an object play behaviour in macaques: Welfare and neurological health implications of a bio-culturally driven tradition. Behaviour, 153, 845-869.

Owen, K., Dunlop, R., \& Donnelly, D. (2012). Seaweed interactions by humpback whales (Megaptera novaeangliae): A form of object play? Aquatic Mammals, 38, 18-422.

Packard, J. M. (2003). Wolf behavior: Reproductive, social, and intelligent. In L. D. Mech \& L. Boitani (Eds.), Wolves: Behavior, ecology, and conservation. (pp. 35-65). University of Chicago Press.

Paquette, D., \& Prescott, J. (1988). Use of novel objects to enhance environments of captive chimpanzees. Zoo Biology, 7, 15-23.

Paulos, R. D., Trone, M., \& Kuczaj II, S. A. (2010). Play in wild and captive cetaceans. International Journal of Comparative Psychology, 23, 701-722.

Rabinowitz, F. M., Moely, B., Finkel, N., \& McClinton, S. (1975). The effects of toy novelty and social interaction on the exploratory behavior of preschool children. Child Development, 46, 286-289.

Sanz, C., Call, J., \& Boesch, C. (2013). Tool use in animals: Cognition and ecology. Cambridge University Press.

Sergio, F., Blas, J., Blanco, G., Tanferna, A., Lopez, L., Lemus, J. A., \& Hiraldo, F. (2011). Raptor nest decorations are a reliable threat against conspecifics. Science, 331, 327-330.

Shivik, J. A., Mastro, L., \& Young, J. K. (2014). Animal attendance at M-44 sodium cyanide ejector sites for coyotes. Wildlife Society Bulletin, 38, 217-220.

Stahler D. R., MacNulty D. R., Wayne R. K., vonHoldt B., \& Smith D. W. (2013). The adaptive value of morphological, behavioural and life-history traits in reproductive female wolves. Journal of Animal Ecology, 82, 222-234.

Stenglein, J. L., Waits, L. P., Ausband, D. E., Zager, P., \& Mack, C. M. (2010). Efficient noninvasive genetic sampling for monitoring reintroduced wolves. Journal of Wildlife Management, 74, 1050-1058. 
Theuerkauf, J., W. Jędrzejewski, K. Schmidt, H. Okarma, I. Ruczyński, S. Sniezko, \& R. Gula. (2003). Daily patterns and duration of wolf activity in the Białowieza Forest, Poland. Journal of Mammalogy, 84, 243253.

Tuohy, D. (1982). Another Great Basin atlatl with dart foreshafts and other artifacts: Implications and ramifications. Journal of California and Great Basin Anthropology, 4, 80-106. 